\title{
Comparative analysis of KTA19-C525 and QSX15-C525 engine
}

\author{
JianChun Gong ${ }^{1, a}$, XiYue Wang ${ }^{2, b}$, JianHong Tang ${ }^{2, c}$
}

\author{
${ }^{1}$ School of traffic and automobile engineering, Panzhihua University, Sichuan, 617000, P.R. China \\ ${ }^{2}$ Panzhihua iron and steel (Group) Company mineral company automobile factory building General \\ Factory,617000, P.R. China \\ aemail:jcgong01@163.com, bemail:914157648@qq.com, ${ }^{c}$ email:21152688@qq.com
}

Keywords: TR50 mine truck; 3307 mine truck; QSX15-C525 engine; KTA19-C525 engine; frame .

\begin{abstract}
TR50 mine truck, a new type of mine transporter produced by CHINANHL BUCYRUS, It configure QSX15-C525 engine, produced by Cummins Engine Inc. We compared and analyzed QSX15-C525engine of TR50 mine truck and decided to replace it with KTA19-C525 engine of 3307 mine truck.

The main works done in this dissertation are as follows: The comparison result of technical parameters Chart one The technical parameters of KTA19-C525 engine and QSX15-C525 engine, The comparison result of fuel consumption in different speed Chart two The fuel consumption of KTA19-C525 engine and QSX15-C525 engine, The comparison result of Dimension Chart three The dimension of KTA19-C525 engine and QSX15-C525 engine, Correlation of Vehide Matching and Vehide Computer Control before and after reform Chart four Correlation of Vehide Matching and Vehide Computer Control before and after reform of TR50 mine truck, The comparison result of TR50 mine car and 3307 mine truck about frame.
\end{abstract}

\section{Introduction}

QSX15-C525 engine of TR50 mine truck is imported from America. Our company discovered that some defects about this engine, such as high fault ratio, difficult to troubleshooting, high maintenance costs and time-consuming maintenance, contribute to lower working rate. One of the main causes is that our company lack of tools, instrument equipment and technical data lead to the increased difficulty in maintains result from this new imported engine. On the other hand, all equipment of this engine are import give rise to high operation and maintenance costs and long maintenance cycle (need more than three months to half a year's time to purchase).Since 1987 mining company purchased more than 60 3307mine truck. It is a main hauler for our company. For us the KTA19-C525 engine of 3307mine truck is the mature final product, a comparatively high rate of truck ownership (38 in service as yet), easy to troubleshooting, operating and Maintenance. And most of it's spare and accessory parts are homemade give rise to lower operation and maintenance costs and short maintenance cycle (overhauling engine need about 15 day).In summary, it's necessary to replace QSX15-C525engine of TR50 mine truck with KTA19-C525 engine. The result is good for our company to improve utilization of TR50 mine truck [2] [3] .

\section{Contrastive analyzing the performance parameters of two model engine to ensure the feasibility of replace and transform}

In order to ensure the feasibility of replace and transform, analysis and comparison the performance parameters, fuel consumption, Dimension, Vehide Computer Control and Vehide Matching and vehicle frame of KTA19 - C525 engine and QSX15-C525 engine.

The engine of 3307 mine truck is KTA19-C525 engine (produced by CCEC).

The engine of TR50 mine truck is QSX15-C525 engine (imported from US). 


\section{The comparison result of technical parameters}

Chart 1 The technical parameters of KTA19-C525 engine and QSX15-C525 engine

\begin{tabular}{|c|c|c|}
\hline technical parameters & QSX15-C525 & KTA19-C525 \\
\hline $\begin{array}{c}\text { rating of engine }(\mathrm{hp}) / \text { rated engine } \\
\text { speed }(\mathrm{rpm})\end{array}$ & $525 / 2100$ & $525 / 2100$ \\
\hline maximum engine torque $(\mathrm{N}-\mathrm{M})$ & 2440 & 2237 \\
\hline $\begin{array}{l}\text { maximum power and torque }(\mathrm{hp}) / \\
\text { speed at maximum torque }(\mathrm{rpm})\end{array}$ & $480 / 1400$ & $408 / 1300$ \\
\hline fuel system & HPCR & pt fuel oil system \\
\hline toxic emission & $\begin{array}{l}\text { Two-stage of Mine field } \\
\text { (EN) }\end{array}$ & $\begin{array}{l}\text { First stage of Mine field(fully } \\
\text { meet Chinese standards) }\end{array}$ \\
\hline
\end{tabular}

In summary, the rating of engine and rated engine speed just the same, roughly the same maximum engine torque maximum power and torque and speed at maximum torque. It fully meet the existing discharging standard in our country, despite the negative results of KTA19-C525 engine's toxic emission.

The comparison result of fuel consumption in different speed

Chart2 The fuel consumption of KTA19-C525 engine and QSX15-C525 engine

\begin{tabular}{|c|c|c|}
\hline & \multicolumn{2}{|c|}{ Fuel consumption (g/KW-h) } \\
\hline Speed(RPM) & QSX15-C525 & KTA19-C525 \\
\hline 1200 & 218 & 219 \\
\hline 1300 & 217 & 206 \\
\hline 1400 & 217 & 204 \\
\hline 1500 & 212 & 204 \\
\hline 1600 & 204 & 205 \\
\hline 1700 & 198 & 208 \\
\hline 1800 & 201 & 211 \\
\hline 1900 & 201 & 215 \\
\hline 2000 & 208 & 221 \\
\hline 2100 & 212 & \\
\hline
\end{tabular}

At the speed of 1200-1600 rpm, the fuel consumption of KTA19-C525 engine is lower than QSX15-C525 engine. And at the speed of 1600-2100, the fuel consumption are opposite. The refitted TR50 mine truck is used to hauling up the Zhujiabaobao Mine. The heavy haulage like this led to high rotation speed and the fuel consumption of KTA19-C525 engine is a little more than QSX15-C525 engine. This little difference means that transform is feasible [4] .

The comparison result of Dimension

Chart 3 The dimension of KTA19-C525 engine and QSX15-C525 engine

\begin{tabular}{|c|l|l|}
\hline item & \multicolumn{1}{|c|}{3307 mine truck } & \multicolumn{1}{c|}{ TR50 mine truck } \\
\hline $\begin{array}{c}\text { The mounting dimensions of } \\
\text { engine }\end{array}$ & $\begin{array}{l}\text { The distance of front engine } \\
\text { seat is 15CM, rear engine seat } \\
\text { is 76.5CM. The distance } \\
\text { between front and rear engine } \\
\text { seat is 145CM. }\end{array}$ & $\begin{array}{l}\text { The distance of front engine } \\
\text { seat is 33CM, rear engine seat } \\
\text { is 92CM. The distance } \\
\text { between front and rear engine } \\
\text { seat is 133CM. }\end{array}$ \\
\hline $\begin{array}{c}\text { The way of connecting } \\
\text { between the gearbox and } \\
\text { engine }\end{array}$ & $\begin{array}{l}\text { Front propeller shaft and } \\
\text { gearbox front fork (Type A) }\end{array}$ & $\begin{array}{l}\text { Front propeller shaft and } \\
\text { gearbox front fork (Type B) }\end{array}$ \\
\hline The dimension of engine & \multicolumn{1}{|c|}{$1600 * 700 * 1350$} & \multicolumn{1}{|c|}{$1350 * 550 * 1180$} \\
\hline
\end{tabular}


The way of connecting between the gearbox of TR50 mine truck and KTA19-C525 engine is exact match and the little difference of dimension mean sufficient space install the KTA19-C525 engine [5] .

Correlation of Vehide Matching and Vehide Computer Control before and after reform

Chart 4 Correlation of Vehide Matching and Vehide Computer Control before and after reform of

TR50 mine truck

\begin{tabular}{|c|c|c|}
\hline item & before reform & after reform \\
\hline Engine Wiring & ECM and other respectively Engine Wiring & abandon \\
\hline transmission harness & $\begin{array}{c}\text { transmission wiring harness T, vehicle body } \\
\text { wiring harness V, shifting wiring harness S }\end{array}$ & invariant \\
\hline transmission sensor & $\begin{array}{c}\text { Output Sensor Turbine Sensor、 revolution } \\
\text { speed transducer }\end{array}$ & invariant \\
\hline $\begin{array}{c}\text { Computerized } \\
\text { Version }\end{array}$ & New ECU, 24V & invariant \\
\hline
\end{tabular}

Initially, KTA19-C525 engine use PT fuel-control system and have no use for ECM after reform. Furthermore, others are the same electronic-controlled system .From what has been discussed above, we can draw the conclusion that it does not affect the correlation.

The comparison result of TR50 mine truck and 3307 mine truck about frame

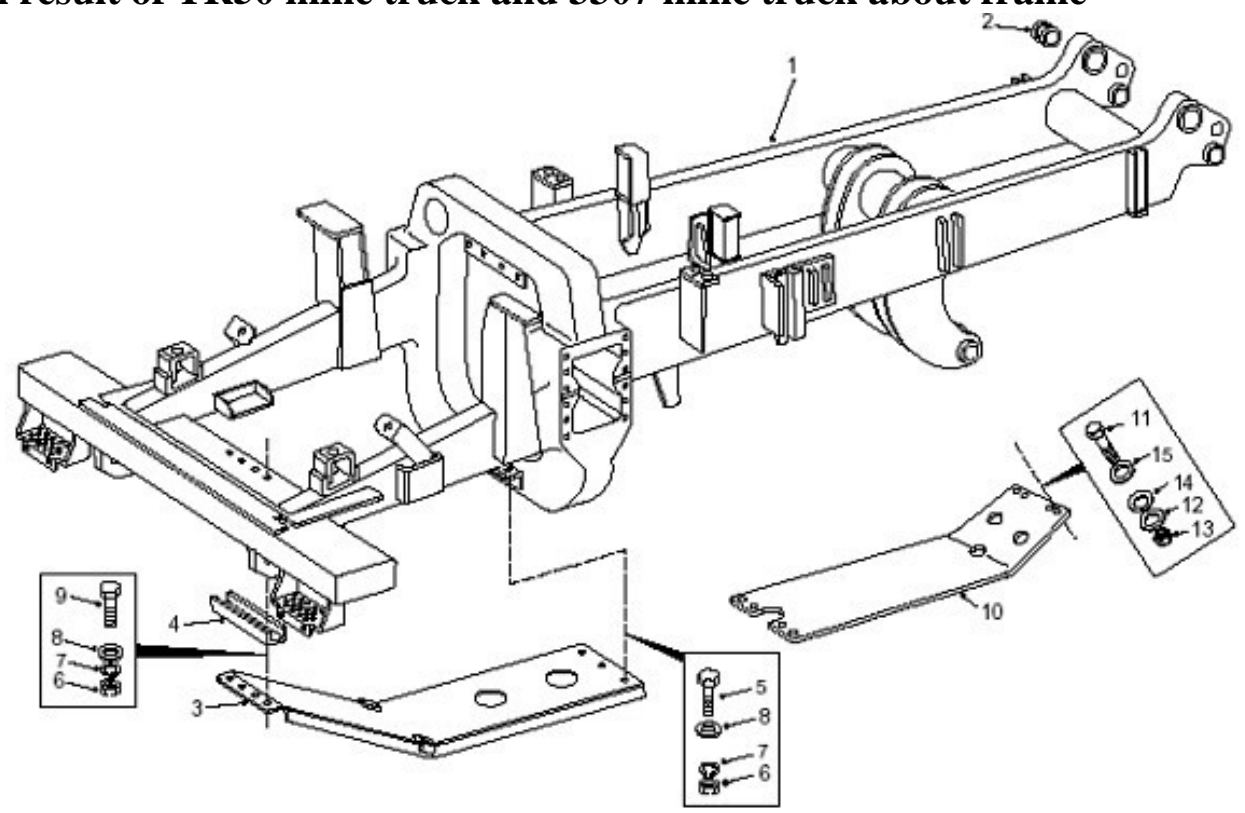

Fig.1. the frame of TR50 mine truck 


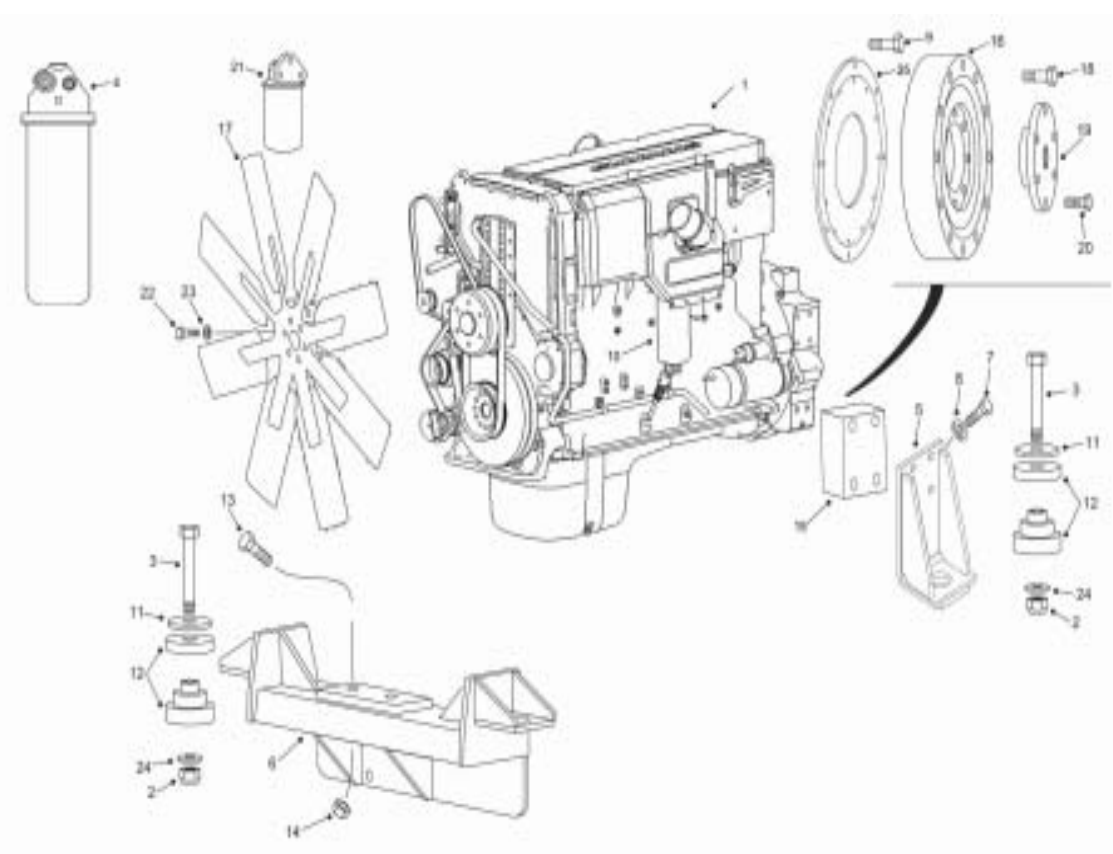

Fig.2.QSX15-C525 engine assembly

Assembly (1) adopt three-point-supporting Installed on the frame (see Figure 1) through the front cross beam (6) and latter bracket (5).Damping rubber (12) Installed between the engine and the bracket, and it should flexibility enough to absorb torsional shock from engine. There is a full-flow oil filter on the bottom left of engine (1), the Filter element of this full-flow oil filter can rotate and replace. Engine oil go from oil pumps to each moving element of engine (1) with going through oil-filter. Engine oil is pressed by oil pump, then pour into the filter element via the oil duct of oil-filter. The filtered oil drained out of the other oil duct. By pass water filter contains coolant additive is compactly arranged on the front right of the engine. More information about these problems can be found at the cooling system related chapters. This engine own two series-wound oil-filter. The primary one is installed in the front left of engine to separate emulsifying water and impurity in the fuel. The other with oil-water sensor in the bottom is installed in the left of engine [1] .

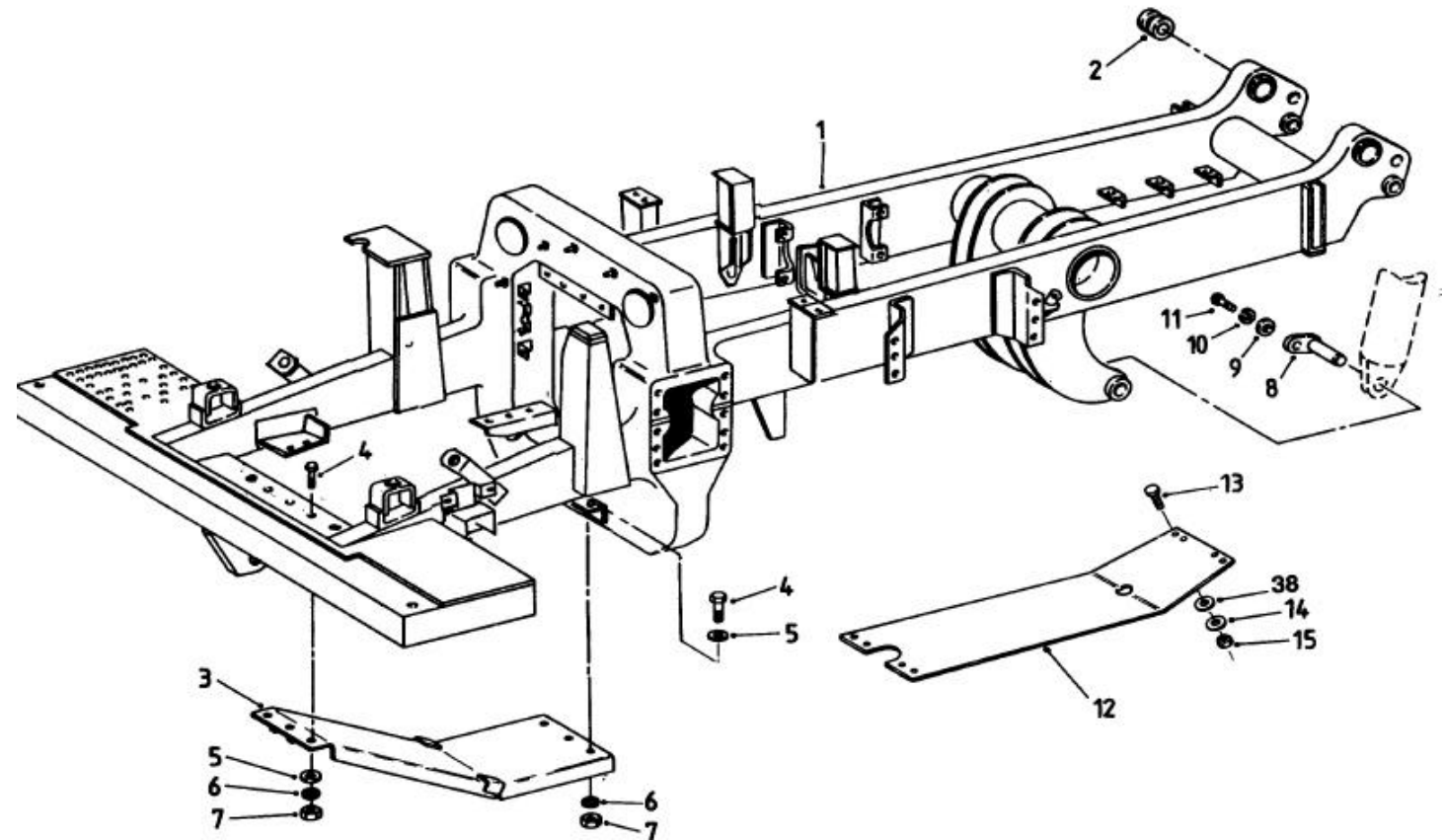

Fig.3. the frame of 3307 mine truck 


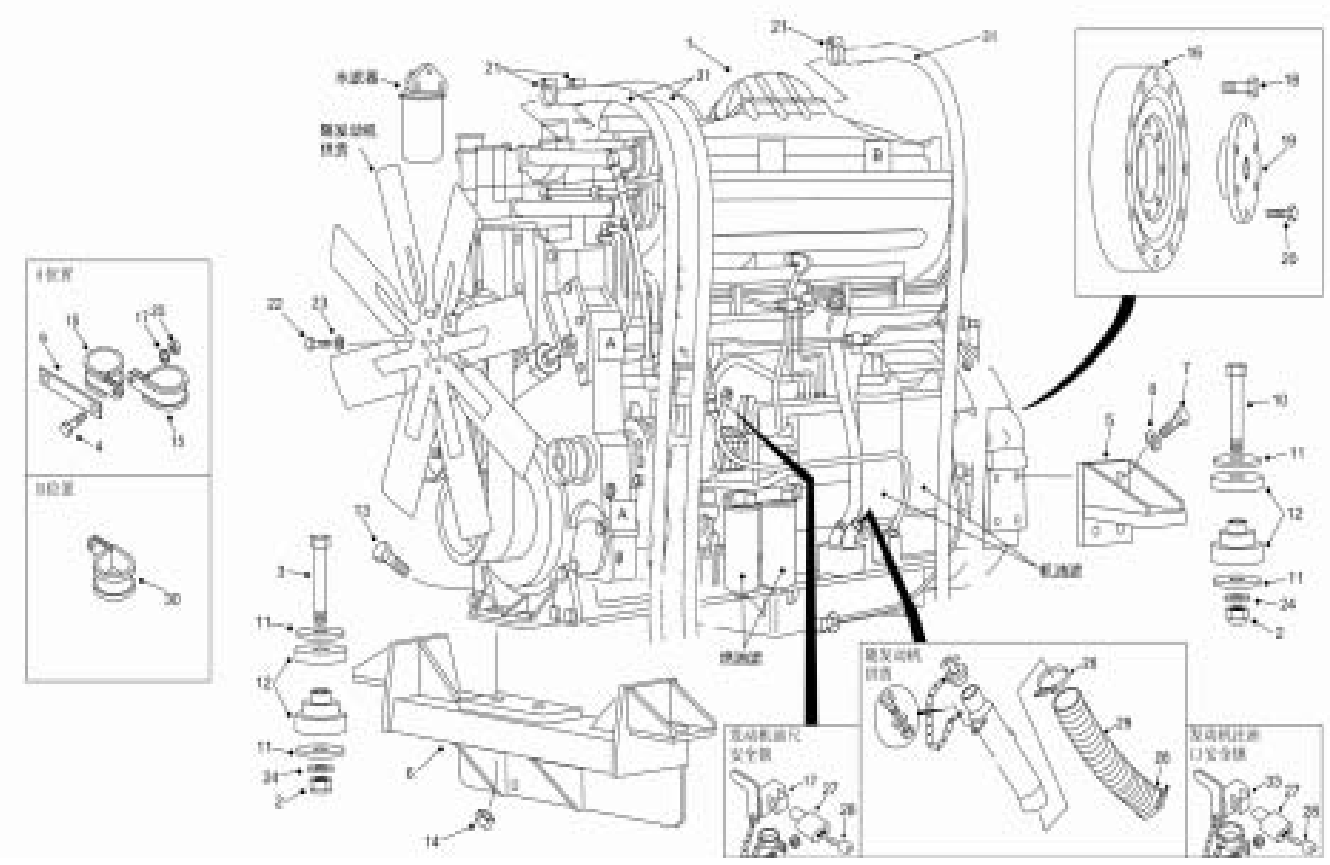

Fig.4. KTA19-C525 engine assembly

Assembly adopt three-point-supporting Installed on the frame (see Figure 3) through the front cross beam (6) and latter bracket (5). Damping rubber (12) Installed between the engine and the bracket, and it should flexibility enough to absorb torsional shock from engine. There is a full-flow oil filter on the bottom left of engine (1), the Filter element of this full-flow oil filter can rotate and replace. Engine oil go from oil pumps to each moving element of engine (1) with going through oil-filter. Engine oil is pressed by oil pump, then pour into the filter element via the oil duct of oil-filter. The filtered oil drained out of the other oil duct. By pass water filter contains coolant additive is compactly arranged on the front right of the engine. Two rotatable oil-filter are installed in the left of engine. Impurity in oil are separated out via oil-filter.

In summary, two kinds of mine truck own the forms parallel structures. There are some major difference in the installation position of engine base, the front cross beam and the bottom plate, but can be done through transformation.

\section{Conclusion}

In summary, it is feasible to substitute KTA19-C525 engine for QSX15-C525 engine of TR50 mine truck regardless of Dimension, Vehide Computer Control and Vehide Matching and vehicle frame. The fuel drain of engine reach the first stage of Mine field ( fully meet Chinese standards ) even though lower emissions [6].Some problem about install KTA19-C525 engine on TR50 mine truck can be solved by means of transform. It ensured all the practical technical performance of TR50 mine truck and achieved the spare parts localization bring about supply flowing. Moreover, it apparently shortens maintenance duration and low the use-cost and maintenance cost. Furthermore, it reduced the difficulty of maintenance, shot the fault quickly and easily, obviously enhanced utilization rate of TR50 mine truck. Above all, economic comprehensive benefit are remarkable.

\section{Reference}

[1] Gong JC, Shi WK. Analysis and compensation of the tip pose error in 6-pss parallel mechanism. Metalurgia 2013; vol. XVIII Special Issue no. 4:264-267.

[2] Lu L, Wang J, Yang P. The influences of surface rough under the condition of oil starvation to the non-Newtonian point contact thin film lubrication. Triboloji 2011; 36: 68-72.

[3] Yang Wanfu. Principle and car engine performance. Beijing: higher education press, 2004 . 
[4] Kong Xianhui. Zhang Guangkun. Automobile fault diagnosis technology. Beijing: higher education press. 2002.

[5] zi-bo zhang. Automobile engine construction and maintenance. . Beijing: higher education press, 2005.

[6] Chen Rui etc. Steam structure. Beijing: people's traffic press, 2003. 